\title{
A Phase Theoretic Account of Coreference Relations in Picture DPs
} Jason Ginsburg (University of Aizu), Sandiway Fong (University of Arizona)

\section{Introduction}

An experimental study of native speaker judgments of picture DPs by Keller \& Asudeh (2001) found that pronouns and anaphors are in complementary distribution in some cases $(1 \mathrm{a}-\mathrm{b})$ and $(1 \mathrm{c}-\mathrm{d})$, but not in others (1e-f).
(a) ?*Hannah ${ }_{i}$ found a picture of her . $_{\text {. }}$
(b) Hannah $_{i}$ found a picture of herself . $_{\text {. }}$
(c) ?*Hannah found Peter $_{i}$ 's picture of him $_{i}$.
(d) Hannah found Peter ${ }_{i}$ 's picture of himself . $_{i}$
(e) Hannah ${ }_{i}$ found Peter's picture of her . $_{\text {. }}$
(f) $\operatorname{Hannah}_{i}$ found Peter's picture of herself . $_{\text {. }}$

These facts are at odds with the traditional Binding Theory. (1a-b) and (1c-d) are in accord with Principles A and B (2a-b) and (1e) is in agreement with Principle B. However, a problem is that (1f) violates Principle A.

(2) (a) Principle A: An anaphor must be bound in a local domain.

(b) Principle B: A pronoun must be free in a local domain. (Chomsky 1995:96)

In this paper, we demonstrate how a revised theory of coreference relations that relies on independently motivated elements of Phase Theory (Chomsky 2001, Chomsky 2004) predicts these empirically tested grammaticality judgments.

\section{Background}

Our analysis assumes a version of Phase Theory (Chomsky 2001, Chomsky 2004). In Phase Theory, a derivation proceeds in phases, and the complement of a phase head is sent to Spell-Out separately from a phase edge, as required by the Phase Impenetrability Condition.

Our analysis builds on work by Kayne (2002), who proposes that pronoun-antecedent coreference relations originate from base generation of a doubling constituent of the form [Spec Head] where the Spec is the antecedent and the head is the pronominal, as in (3a). A Spec can move out of a doubling constituent, but a head cannot. However, the Spec can only move out of a doubling constituent if the doubling constituent has moved. In addition, a reflexive DP (e.g., himself) contains a position for the doubling constituent to move to, as in $(3 b)$.

(a) $\left[\operatorname{John}_{i} \operatorname{him}_{i}\right]$ (b) $\left[\left[\operatorname{John}_{i} \operatorname{him}_{i}\right]\left[\operatorname{John}_{i} \operatorname{him}_{i}\right]\right.$ self $]$

However, a problem for this analysis is that it is not clear why a doubling constituent must move in order for the Spec to be extracted.

\section{Proposals}

We assume a modified version of Kayne's doubling constituent proposal. We propose that an R-expression is the complement of a pronominal. A pronoun and antecedent have the structure in $(4 a-b)$. 
(a) $\left.{ }_{D P} \mathrm{D}\left[{ }_{N P} \operatorname{Pron}_{i}\left[{ }_{D P} \mathrm{R}-\mathrm{Exp}_{i}\right]\right]\right]$ (b) $\left[{ }_{D P} \mathrm{D}\left[{ }_{N P} \mathrm{her}_{i}\left[{ }_{D P} \mathrm{Hannah}_{i}\right]\right]\right]$

An anaphor and antecedent originate in a phase $\mathrm{D}^{*} \mathrm{P}$ with a $\mathrm{D}^{*}$ phase head 'self' (5a-b). Morphological merger results in pronunciation of an anaphor as 'herself/himself'.

$$
\text { (a) }\left[{ }_{D * P}\left[{ }_{D *} \operatorname{self}\right]\left[{ }_{N P} \operatorname{Pron}_{i}\left[{ }_{D P} \mathrm{R}-\operatorname{Exp}_{i}\right]\right]\right] \text { (b) }\left[{ }_{D * P}\left[{ }_{D *} \operatorname{self}\right]\left[{ }_{N P} \operatorname{her}_{i}\left[{ }_{D P} \mathrm{Hannah}_{i}\right]\right]\right]
$$

Crucially, a pronoun and anaphor originate in a non-phase DP (4), whereas a pronoun and anaphor originate in a strong phase $\mathrm{D}^{*} \mathrm{P}(5)$.

Our proposal does away with the requirement that a doubling constituent move in order for its Spec to be extracted. Rather, movement occurs via a process of Last Resort, based on the notion that Last Resort operations can save a derivation (cf. Chomsky 1995, Bošković 2007, among others). We assume a modified version of the PIC, whereby when a (strong) phase head is Merged, an entire lower phase is sent to Spell-Out. Last Resort (6a) enables an LI to escape from a phase without moving to a phase edge. In $(6 \mathrm{~b}), \mathrm{X}^{*}$ and $\mathrm{Y}^{*}$ are phase heads. When $\mathrm{X}^{*}$ is Merged, the $\mathrm{Y}^{*}$ phrase $\left(\mathrm{Y}^{*} \mathrm{P}\right)$ will be sent to Spell-Out. $\mathrm{Z}$, with an unvalued feature, is reinserted into the current subnumeration as a Last Resort. It is then selected and Re-Merged at the $\mathrm{X}^{*} \mathrm{P}$ edge, where its unvalued feature is checked.

(6) (a) Last Resort: A Lexical Item (LI) with an unvalued feature, when contained within a phrase that is about to be sent to Spell-Out, is reinserted into the current working subnumeration.

(b) Last Resort: $\left[X * P \mathrm{Z}_{[\text {Feat:X] }} \mathrm{X}^{*} \ldots\left[{ }_{Y * P} \mathrm{Y}^{*} \ldots \mathrm{Z}_{[\text {Feat:- }]} \ldots\right]\right]$

\section{Derivations}

We next demonstrate how our proposals predict the judgments in (1a-f). Horizontal lines in tree diagrams indicate phase edges.

The ill-formed derivations of (1a) and (1c), repeated below, proceed as follows.
(a) ${ }^{*} \operatorname{Hannah}_{i}$ found a picture of her $_{i}$.
(b) ?*Hannah found Peter $_{i}$ 's picture of $\operatorname{him}_{i}$.

In (7a), when $\mathrm{v}^{*}$ is Merged, 'Hannah' is not contained within a phase that can be sent to Spell-Out. Thus 'Hannah', which lacks case and a theta-role, cannot undergo the Last Resort process. The subject theta-role does not get assigned and the derivation crashes, as shown in (8a). In (7b), when ' $s$, which we assume is a $D^{*}$ phase head, is Merged, the Last Resort process similarly cannot apply, since 'Peter' is not contained within a phase that can be sent to Spell-Out. The derivation crashes because 'Peter'is not licensed, as shown in (8b).

(a)

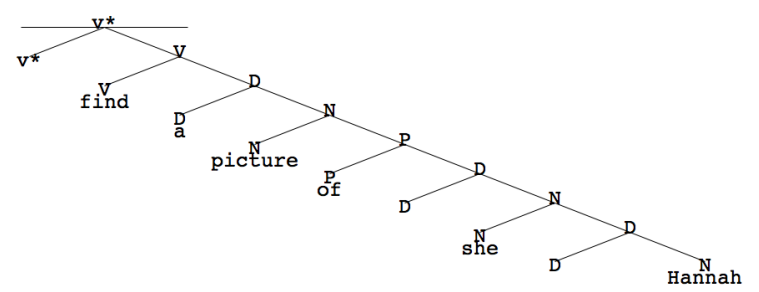

(b)

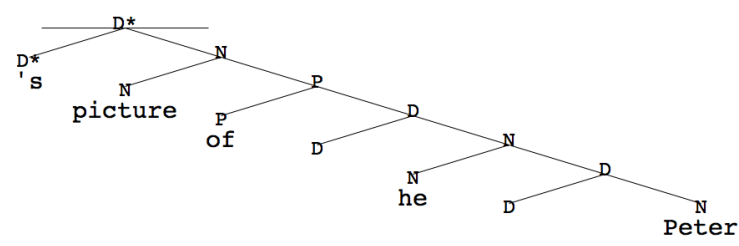

In the well-formed (1b) and (1d), repeated below, the R-expression antecedent is base generated within a $\mathrm{D}^{*} \mathrm{P}$ anaphor. 
(9) (a) Hannah ${ }_{i}$ found a picture of herself ${ }_{i}$. (b) Hannah found Peter ${ }_{i}$ 's picture of himself . $^{\text {. }}$

In (9a), when $\mathrm{v}^{*}$ is Merged, the lower $\mathrm{D}^{*} \mathrm{P}$ anaphor, which is a phase, is sent to Spell-Out. 'Hannah', which lacks case and a theta-role, undergoes the Last Resort process. 'Hannah' is reinserted into the current subnumeration. Then it is selected and Re-Merged at the ${ }^{*} \mathrm{P}$ edge where it receives a theta-role, after which it moves to the TP edge to satisfy an EPP feature and obtain case, as shown in (10). In (9b), we assume that the $\mathrm{D}^{*}$ 's $s$ is a phase head. Therefore, when $\mathrm{D}^{*}$ 's is Merged, the lower $\mathrm{D}^{*} \mathrm{P}$ anaphor phase is sent to Spell-Out. Since 'Peter' has unvalued features, the Last Resort process applies. 'Peter' is reinserted into the current subnumeration and is then selected and Re-Merged at the picture $\mathrm{D}^{*} \mathrm{P}$ edge, where it is licensed, as shown in (11).

(10)

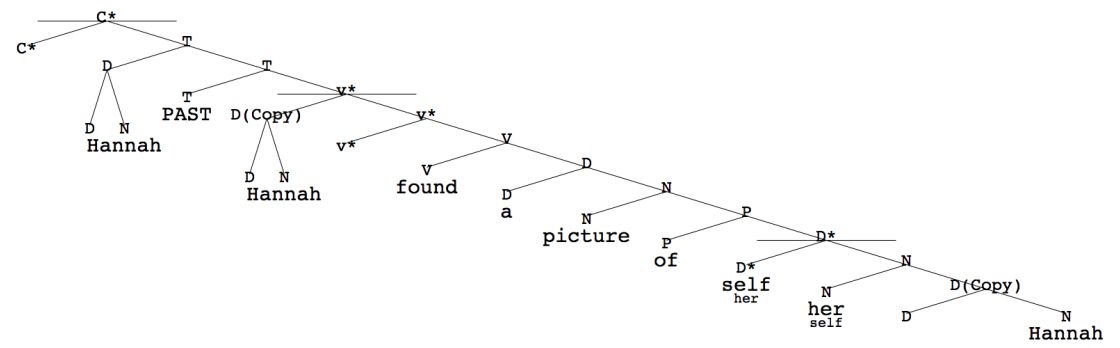

(11)

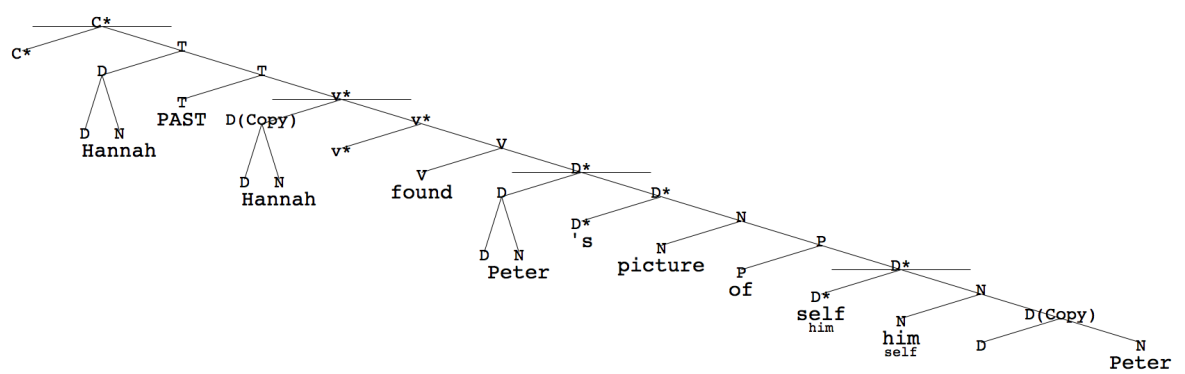

Lastly, this analysis predicts the possibility of either an anaphor or a pronoun in a picture $\mathrm{D}^{*} \mathrm{P}$, as in (1e-f), repeated below.

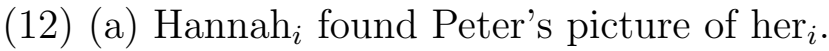

(b) $\mathrm{Hannah}_{i}$ found Peter's picture of herself $_{i}$.

In each of these constructions, the Last Resort process enables the R-expression 'Hannah' to move out of the doubling constituent and be re-Merged in theta-position. In (12a), when $\mathrm{v}^{*}$ is Merged, the picture $\mathrm{D}^{*} \mathrm{P}$ is sent to Spell-Out. Last Resort applies and 'Hannah', due to its unvalued features, is reinserted into the current subnumeration. 'Hannah' is then selected and Re-Merged at the $\mathrm{v}^{*} \mathrm{P}$ edge, where it is licensed, as shown in (13). In (12b), when the $\mathrm{D}^{*}$ 's is Merged, the anaphor $\mathrm{D}^{*} \mathrm{P}$ is sent to Spell-Out. Thus, Last Resort applies and 'Hannah' is reinserted into the current subnumeration. 'Hannah' is selected and Re-Merged at the edge of the picture $\mathrm{D}^{*} \mathrm{P}$. It is not licensed in this position. This is a process of adjunction forced by the need to empty out a subnumeration. When $\mathrm{v}^{*}$ is Merged, 'Hannah' again undergoes the Last Resort process. It is reinserted into the current subnumeration. 'Hannah' is selected and Re-Merged at the $\mathrm{v}^{*} \mathrm{P}$ edge, where it is licensed, as shown in (14). 
$(13)$

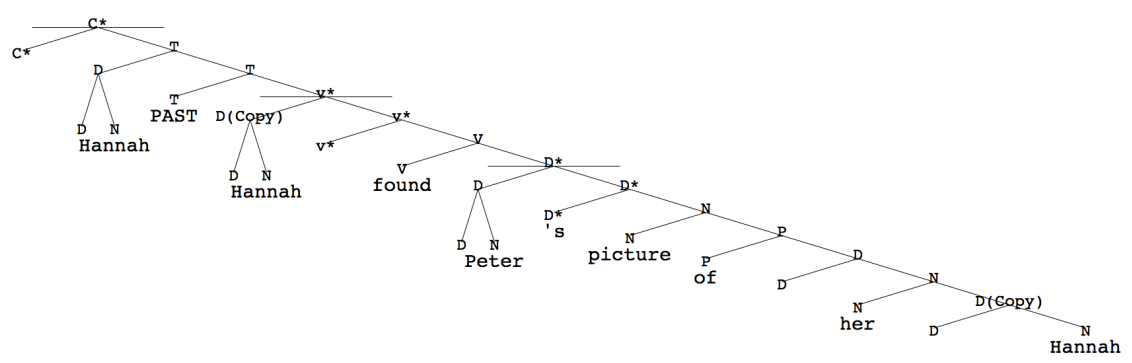

$(14)$

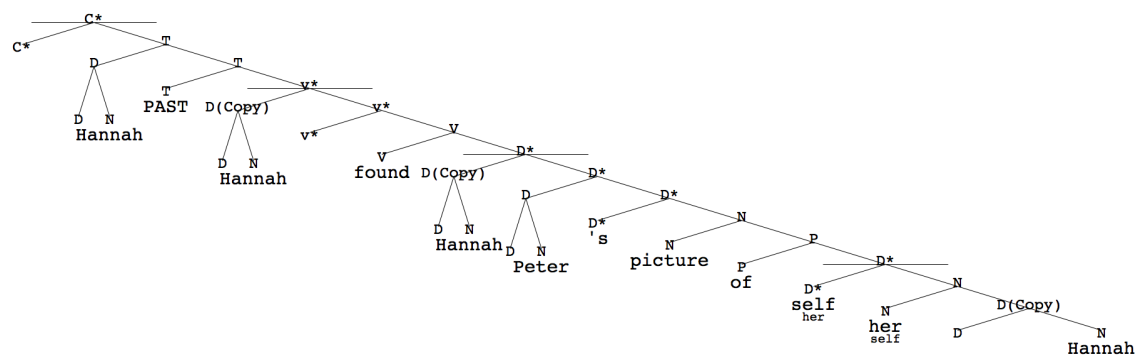

\section{Conclusion}

This analysis predicts the grammaticality judgments in (1a-f), as found by Keller \& Asudeh (2001). In particular, the perplexing possibility of both an anaphor and pronoun in (1e-f) is accounted for. Coreference relations are accounted for in terms of base generation of a pronoun and antecedent within a DP/D*P, and the possibility of Last Resort movement (that can carry an R-expression into theta-position) as determined within the confines of Phase Theory.

\section{References}

BošKović, ŽELJKo. 2007. On the locality and motivation of Move and Agree: An even more minimal theory. Linguistic Inquiry 38.589-644.

Chomsky, NoAm. 1995. The Minimalist Program. Cambridge, MA: MIT Press.

—. 2001. Derivation by phase. In Ken Hale: a life in language, ed. by Michael Kenstowicz, 1-52. Cambridge, MA: MIT Press.

—. 2004. Beyond explanatory adequacy. In Structures and beyond: The cartography of syntactic structures, volume 3, ed. by Adriana Belletti, 104-131. Oxford, UK: Oxford University Press.

Kayne, Richard. 2002. Pronouns and their antecedents. In Derivation and explanation in the Minimalist Program, ed. by Samuel David Epstein \& T. Daniel Seely, 133-166. Malden, MA: Blackwell Publishing.

Keller, Frank, \& Ash Asudeh. 2001. Constraints on linguistic coreference: Structural vs. pragmatic factors. In Proceedings of the 23rd Annual Conference of the Cognitive Science Society, ed. by Johanna D. Moore \& Keith Stenning, 483-488. Mahawah, NJ: Lawrence Erlbaum. 